\title{
Continuous and High Flow Gauging System for Surface and Underground Liquid Fuel Storage Tanks in Colombia
}

\author{
G. Gustavo A. Ospitia, L. Julián R. Camargo and Ch. César A. Perdomo* \\ Universidad Distrital Francisco José de Caldas, Bogotá D.C., Colombia; gospitia@correo.udistrital.edu.co, \\ jcamargo@udistrital.edu.co,cperdomo@udistrital.edu.co
}

\begin{abstract}
Objectives: In this paper, the aim is to show how to generate a gauging table with the continuous use of electrical, hydraulic and mechanical devices that aim to provide reliability, purity and industrial safety, by not directly manipulating the fuel and actions that may vary final product or induce accidents. In addition, by making a custom gauging table for the arbitrary conditions of the tank, the uncertainty about the quantity of the liquid is reduced and, therefore, it does not discriminate on the type, shape or physical characteristics of these, because the characteristic of the tank it is carried out in the place and under the operating conditions. Methods/Analysis: The model was developed in five stages, a saber: Analysis and specification, Design and construction, Evaluation, Modification and Testing. Findings: Through the implementation of this measure system reliability, safety, and decreased operating time thanks to a methodology of continuous high flow samples and offers. Improvements: The developed model can evolve to a system with greater automation, using level and flow sensors with the same or better resolution, which does not have its own interface for reading but can be added to the communication card and flow control, needing a single USB communication port for mobile phones, with the aim of developing the application on mobile phones.
\end{abstract}

Keywords: Flow, Gauging, Storage Tank, Threats, Volumetric Filling

\section{Introduction}

In Latin America, several projects of gauging in the hydrocarbon sector have been carried out (process to determine the total capacity of the liquid storage tank, or the corresponding partial capacities at different heights $)^{1}$. In Ecuador, the practice of tank gauging is mainly done through volumetric calibration of surface hydrocarbon storage tanks achieving the registration of height measurements (measuring tape), flow (fluxometer), and mathematical corrections respect to parameters that affect the reliability of the measurement such as temperature, inclination and coefficient of expansion of the liquid ${ }^{2}$.

In Colombia, a lot of work has been done in this sector and it has three outstanding projects, two of them from the ATP Ingeniería LTDA company and the third one from the Leona brewery.The first one of the ATP Ingeniería LTDA company whose objective is to know telemetrically from
Labview the data of the inspection teams (Panametrics, PCM and CIPS), to then elaborate the gauging table of the surface hydrocarbon tanks, and the transport lines by means of ultrasound sensors ${ }^{3}$. The second specific project for the implementation of a tank radio control robot, whose function is to scale vertically the tank and monitor the presence of the liquid to obtain the gauging table $e^{4}$. The third project implemented in the Leona brewery, designs and implements a gauging system for finished beer tanks controlled by means of an S7-200 PLC, flow and level sensors by ultrasound at the time of filling.

The previous projects have served as a guide for the realization of this article. Therefore, this document presents the development of a continuous and high flow gauging system for storage tanks of surface and underground liquid fuels through the implementation of a hydraulic, electrical and electronic circuit that, through a program specialized in the process, controls and monitors the process through an

${ }^{*}$ Author for correspondence 
interface that is manipulated by the operator. The hydraulic circuit fulfills the function of up to 100 gallons per minute that is accounted by two electronic circuits, in addition to detecting, communicating and controlling the flow.

All the information is centralized in a software application in charge of receiving data from the sensors simultaneously using threads, making the process quick and agile, leading to visualization, tabulation and controlling the process in real time. The software apart from the previous tasks, must provide graphic and tabulated reports; the graphical reports are executed in the course of the program providing a summary for the end user, the tabulated reports can be delivered in a partial or final way to the user's choice and are generated in the Microsoft Excel program with the purpose of customizing it to the user's liking final.

\section{Volumetric Method in Fuel Tanks}

The importance of this method lies in generating reliability in the measurements of different types of tanks such as underground, surface or high with irregular deformations, geometric variations and inclinations. To achieve this, it has a flow and height meter (tape, 3 meter ruler, manual or electronic height measuring device), all of this can be seen in Figure 1.

The procedure can be executed in two ways:

- By filling: applies to underground or surface tanks.

- By emptying: applies only to surface tanks; to carry out this activity, it requires a storage space for fuel equal to or greater than the volumetric tank and, as a consequence, the production time and the quantity of components for transporting this flammable liquid increases $\underline{\underline{5}}$.

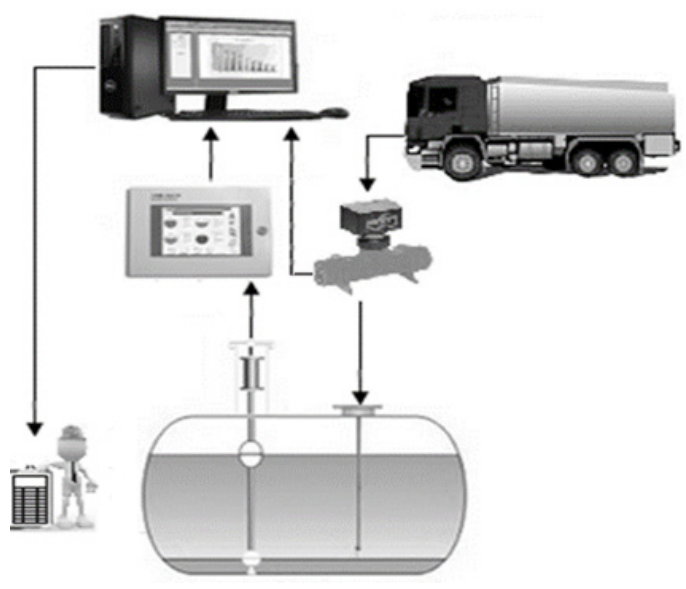

Figure 1. Volumetric filling method for a fuel service station.

\section{Methodology}

The system was designed using the volumetric filling method; for this, it was necessary to implement a hydraulic circuit, an electric and an electronic circuit, in addition, the software in charge of visualizing the information and offering graphical and tabulated reports. In Figure 2 the general diagram of the process is shown.

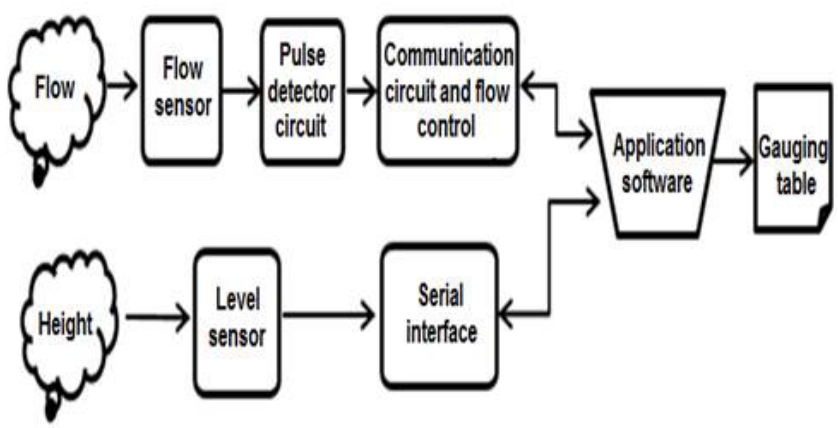

Figure 2. General diagram of the gauging system.

\subsection{Hydraulic Circuit}

The objective of the hydraulic circuit is to supply up to 100 gallons per minute in the pipe, so a galvanized pipe of $1 \frac{1 / 2}{2}$ inches is required in the majority of the circuit. It also has a low-pressure motor pump that carries a flow of 108 gallons per minute ${ }^{6}$. The flow of the circuit is monitored by a helical wheel gear flow sensor that can maintain a constant flow per turn ${ }^{\underline{7}}$. It is controlled manually by ball valves ${ }^{-}$and electrically by means of a solenoid valve that is manipulated from the software application or manually thanks to the control switches. The circuit is made up of 3 entrances, 2 of which are auxiliary storage tanks with a capacity of 200 gallons or 757 liters and the other is from the tanker with an equal or smaller tank capacity.

The simulation presented in Figure 3 shows the operation modes of both the electrovalve and the motor pump with the actual parameters extracted from $^{6}$, finally the tanker in the simulation shows a capacity of 12,000 gallons or 45425 liters, but in reality it depends on the tank, likewise on the capacity of the tank, presenting only 1000 liters or 264 gallons due to the little space in the simulation. 

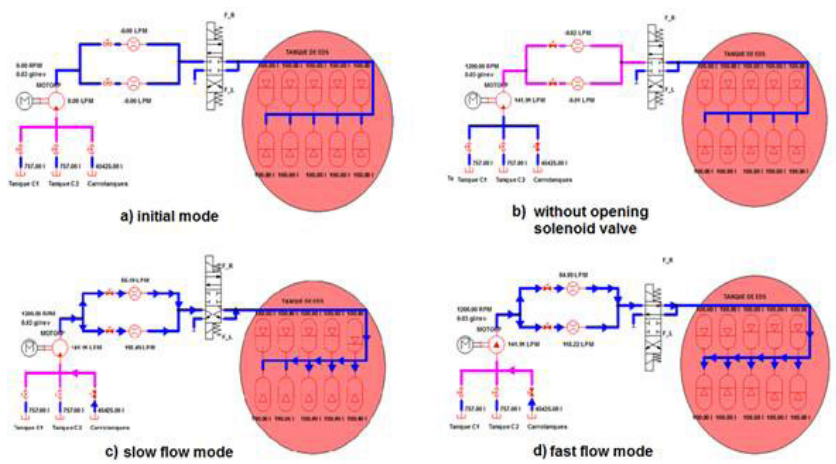

Figure 3. Hydraulic circuit simulation on different modes.

When the process requires emptying the tank in its entirety it is necessary to use an extra pump for the extraction and confinement of the fuel in the auxiliary tanks. It is necessary to take into account the physical-chemical properties of the stored fuel, avoiding contamination with water, mud or other substances, which may affect the system or the end user. When this type of altered fuel is presented, it is then packed in duly sealed containers to be delivered to the certified company in handling hazardous liquids $\stackrel{9}{\text {. }}$

\subsection{Electrical Circuit}

It is responsible for activating, regulating, protecting and supplying the energy necessary for the system. The system is powered by a voltage of $220 \mathrm{VAC}$ and a Neutral. The electrical circuit fulfills the task of delivering AC current to the motor pump, solenoid valve, serial interface and DC to the electronic circuit; it also protects the devices thanks to the motor protector, circuit breakers and fuses, preventing any type of overload or short circuit. In Figure 4 the electrical circuit in the different modes is shown.

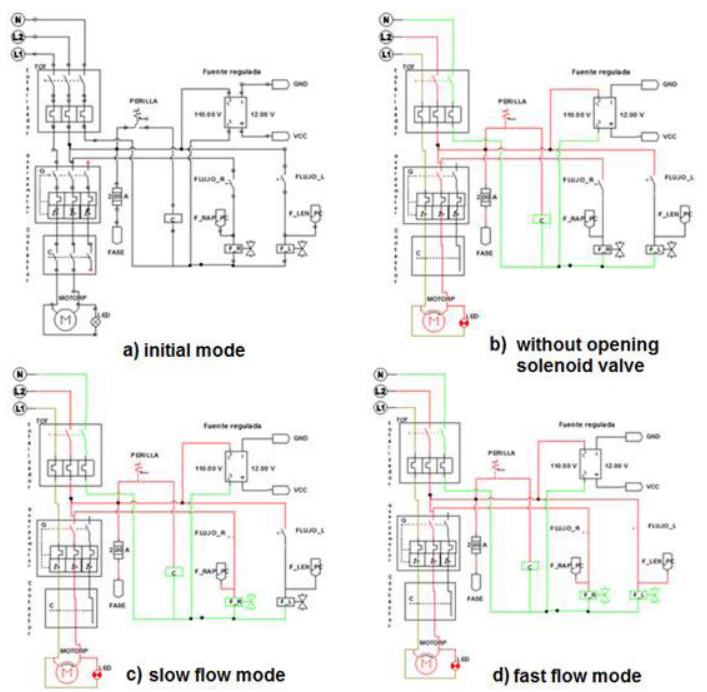

Figure 4. Electric circuit in different operating modes.

\subsection{Electronic Circuits}

They have the task of acquiring the data from the flow sensors, storing the information, establishing a bidirectional communication and controlling the flow of output. To achieve this, two types of circuits were used: pulse detector circuit and communication circuit and flow control.

\subsubsection{Pulse Detector Circuit}

Its function is to convert the mechanical movement of the flow sensor into electrical pulses using an incremental encoder as an encoder, to identify and transmit the information to the communication and flow control circuit (Figure 5).

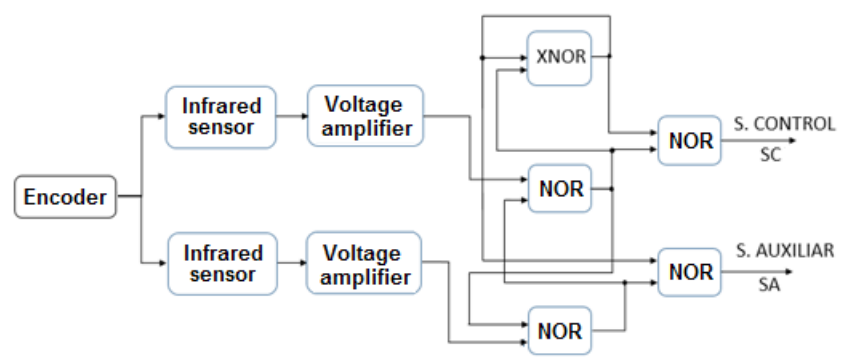

Figure 5. Block diagram pulse detector circuit.

The auxiliary signals (SA in the block diagram of Figure 5) are used in case of emergency when there is a problem with the main ones, although they are complementary signals, the result does not change. The printed circuit board implemented for the pulse detector can be seen in Figure 6 .

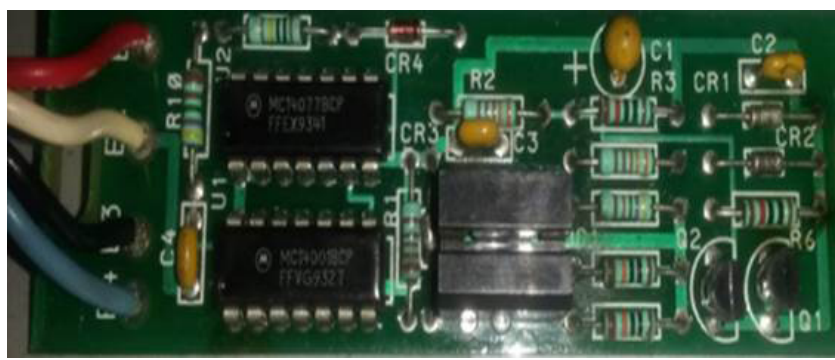

Figure 6. Pulse detector card.

\subsubsection{Communication Circuit and Flow Control}

This circuit has the objective of receiving digital information from the pulse detector cards, and knowing the total amount of fuel that flows at each instant on the flow meter, and then sending it to the software application to be viewed.

The communication with the gauging software is bidirectional through the Debugging Interface of the Circuit (ICDI) through a virtual serial port, using the micro-USB connector. The communication protocol transmits and receives data and control signals such as activating the 
solenoid valve in any of its modes (fast, slow and off) and it's corresponding light indicators (blue, green and red) and restarting the flow information (Figure 7).

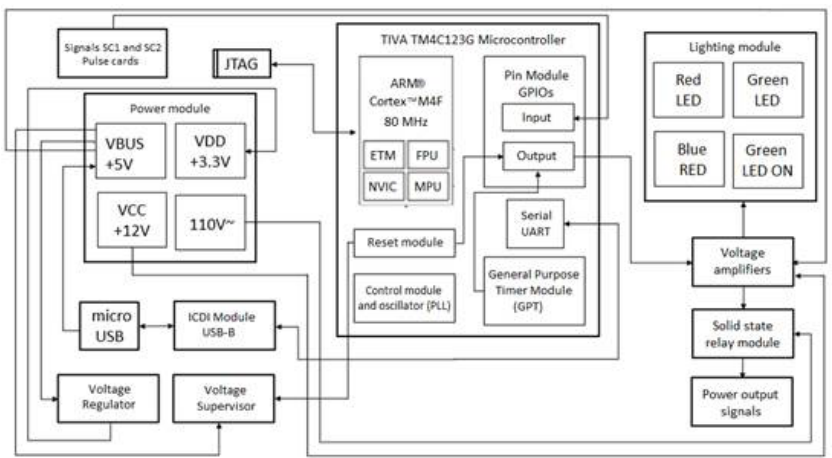

Figure 7. Block diagram communication circuit and flow control.

The result of the printed circuit design for the communication and control card, made in the CAD software application Altium Designer ${ }^{\circledR}$, is shown in Figure 8.

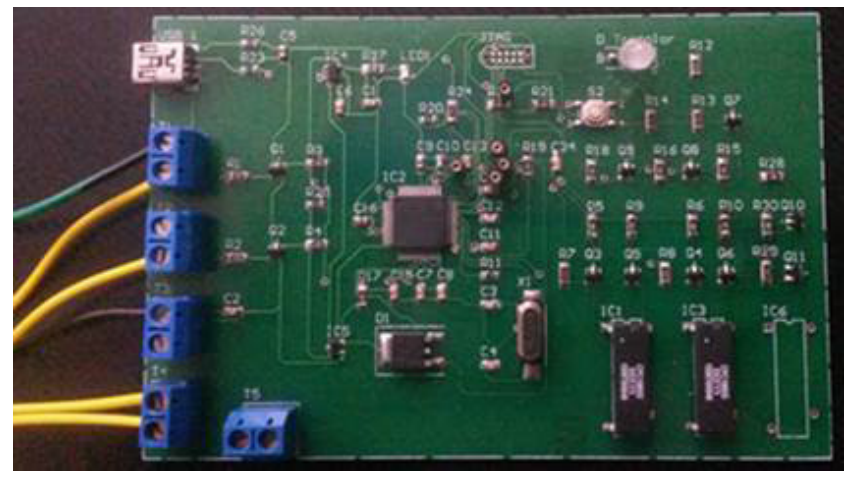

Figure 8. Communication card and flow control.

\subsection{Serial Level Sensor Interface}

The level sensor type magnetostrictive probe meets the specifications (Table 1) of range, resolution and work environment required to obtain a system of continuous and reliable samples thanks to its resolution and accuracy; In addition, it transmits measurements of water level and temperature simultaneously with those of fuel, important variables to know environmental conditions and product quality ${ }^{10}$.

Table 1. Characteristics of the magnetostrictive probe of the 8473 standard

\begin{tabular}{|l|l|}
\hline \multicolumn{2}{|c|}{ CHARACTERISTICS OF THE PROBE } \\
\hline Measuring range & $150-2400 \mathrm{~mm}$ \\
\hline Resolution & $0,1 \mathrm{~mm}$ \\
\hline
\end{tabular}

\begin{tabular}{|l|l|}
\hline Precision & $\pm 0.01 \mathrm{~mm}$ \\
\hline Temperature range & $-40{ }^{\circ} \mathrm{C} \sim 60{ }^{\circ} \mathrm{C}$ \\
\hline Samples by measurement & 20 \\
\hline Material & Stainless Steel \\
\hline Voltage & $<12 \mathrm{~V} \mathrm{DC}$ \\
\hline Current & $<100 \mathrm{~mA}$ \\
\hline Connection & 2 wire \\
\hline
\end{tabular}

The sensor contains two wires, one positive and the other negative necessary for feeding, receiving and sending fuel height values (float 2), water (float 1) and temperature, using the Wiedemann effect, the magnetostriction of the material and a circuit that fulfills the tasks of acquisition, coding, transmission and reception ${ }^{11}$ as shown in Figure 9.

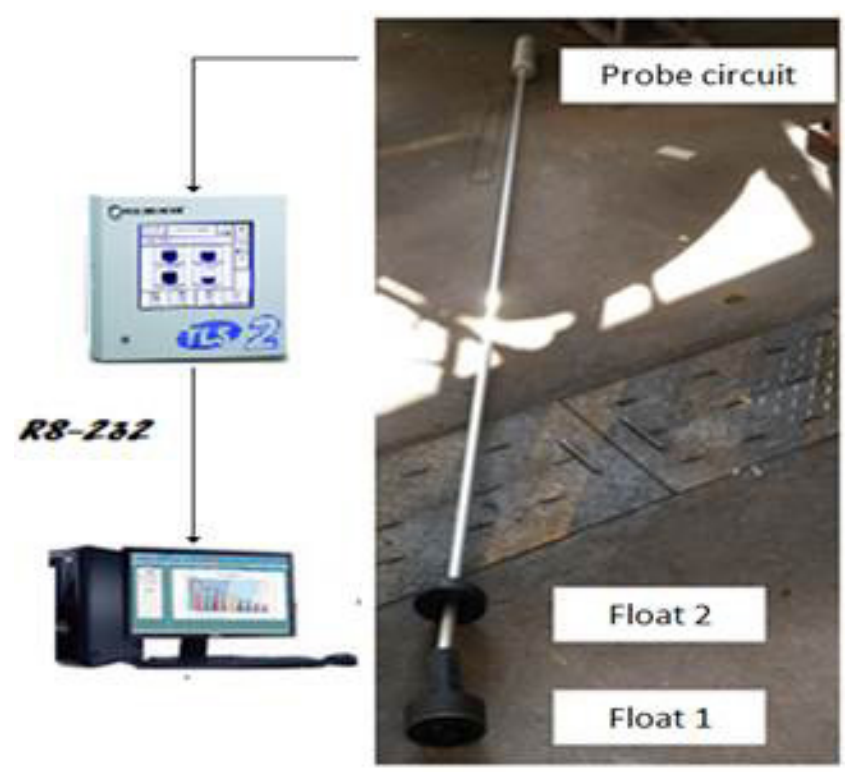

Figure 9. Outline of the serial interface of the probe.

To read data from the Veeder Root probe (fuel height, water height and temperature), the TLS-2 console is used, which is responsible for serially establishing a bidirectional communication with the gauging program $\frac{12}{\text {. }}$.

\subsection{Gauging Software}

The gauging system software is developed through the JAVA programming language, characterized by its free acquisition, distribution and independence of the platform (Windows, Linux, and Mac OS). The gauging software fulfills the communication tasks (communication card and flow control and the serial interface of the magnetostrictive probe), control, configuration, visual- 
ization and generation of reports. Therefore, the software is divided into five parts.

\subsubsection{Authentication}

It is the first part of the software and has the task of restricting the entry by the use of username and password (Figure 10). When the program receives an incorrect user or password, it generates an error message; however, if all the information is correct, it directs it to the configuration form.

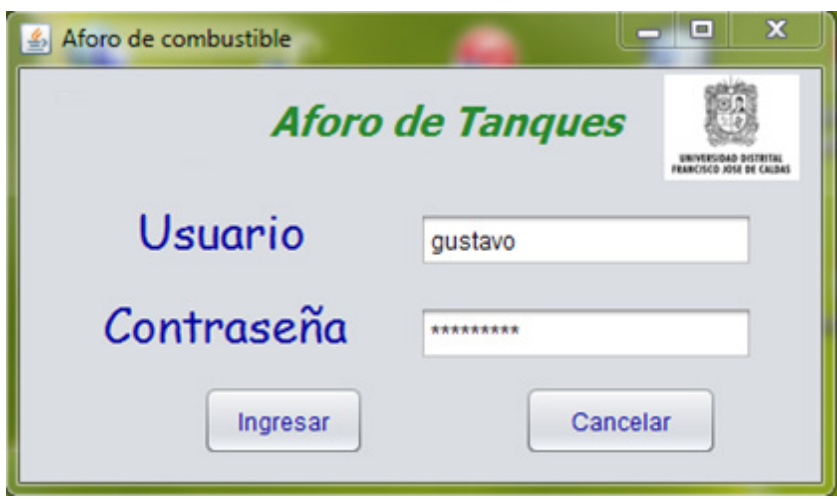

Figure 10. Authentication form.

\subsubsection{Configuration}

Register in text boxes and select through ComboBox the information of the company, characteristics of the tank, information of the communication ports and information of the person responsible for the process (Figure 11). Likewise, you can choose to calibrate the flow sensors or use the default calibration; apart from selecting the start condition (empty or not), having an effect on the control of the visualization of the graphics and the automatic creation of the gauging table.

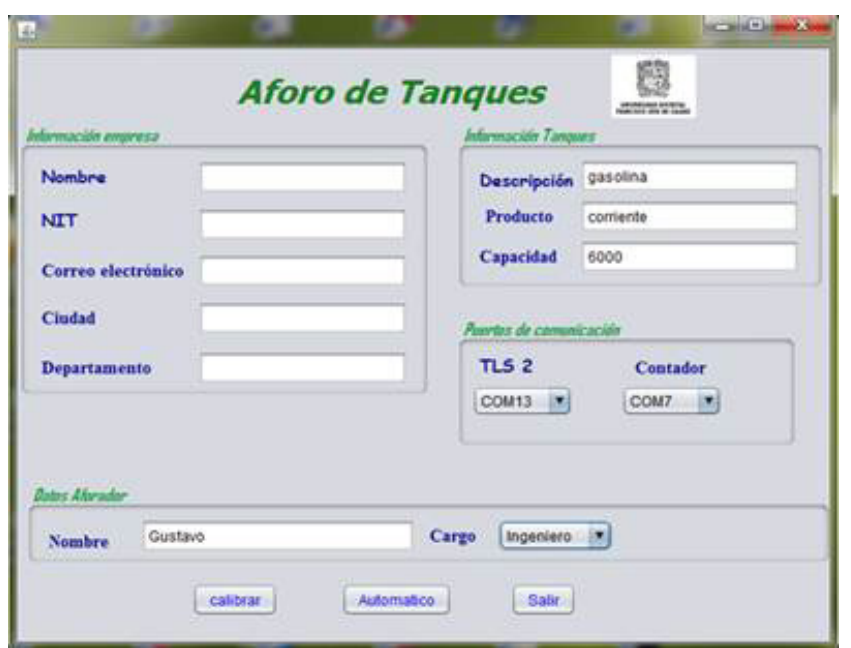

Figure 11. Configuration form.

\subsubsection{Calibration}

Flow sensors require calibration, due to equipment transport or mechanical wear, they must be calibrated separately. For this procedure it is necessary to perform the calibration with a volumetric meter greater than or equal to 50 gallons (Figure 12), by the flow characteristics of the flow sensor.

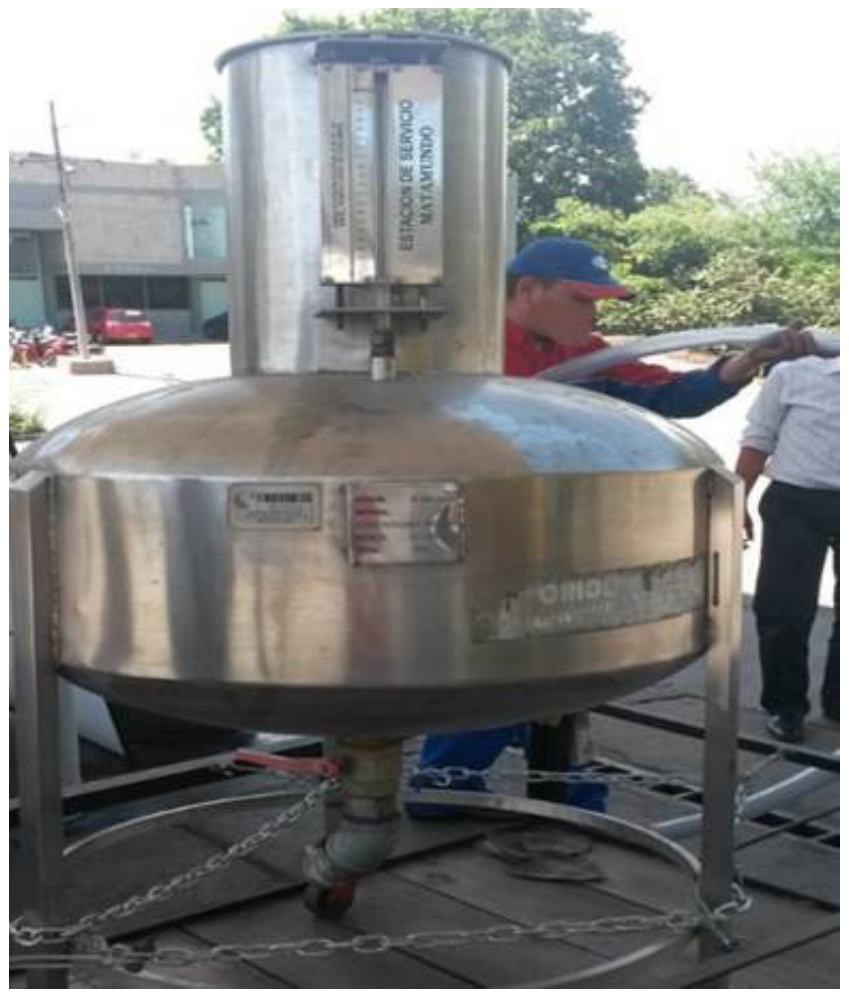

Figure 12. 50-gallon volumetric gauge.

This is the most important part of the process as a result of the implication in reliability of the measurements of the fuel entered. Figure 13 shows the calibration in the software.
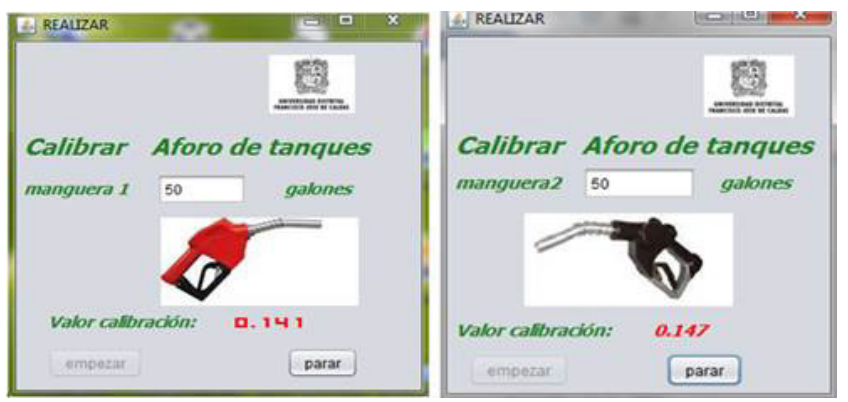

Figure 13. Calibration forms. 


\subsubsection{Process Visualization}

This form (Figure 14) shows the whole process graphically. Starting with the logos, information entered in the configuration form, fuel quantity, tabulation, temperature graphs, water and gauging process, having the property to change scale, colors, print, copy or save; also a tank that shows the fuel level with respect to capacity. This form alerts with green messages changes of height, state of the probe and slow flow. The alarm events that are shown in red or blue are a normal state. Finally, the buttons that have the function of redirecting to the configuration form start or stop the gauging process and save a report of it.

Graphical visualization in the Java language must be managed with graphic event thread called Swing Worker, which has the utility of working in the background all operating processes and great processing, providing the user with a system in real time, both in the visual part as control.

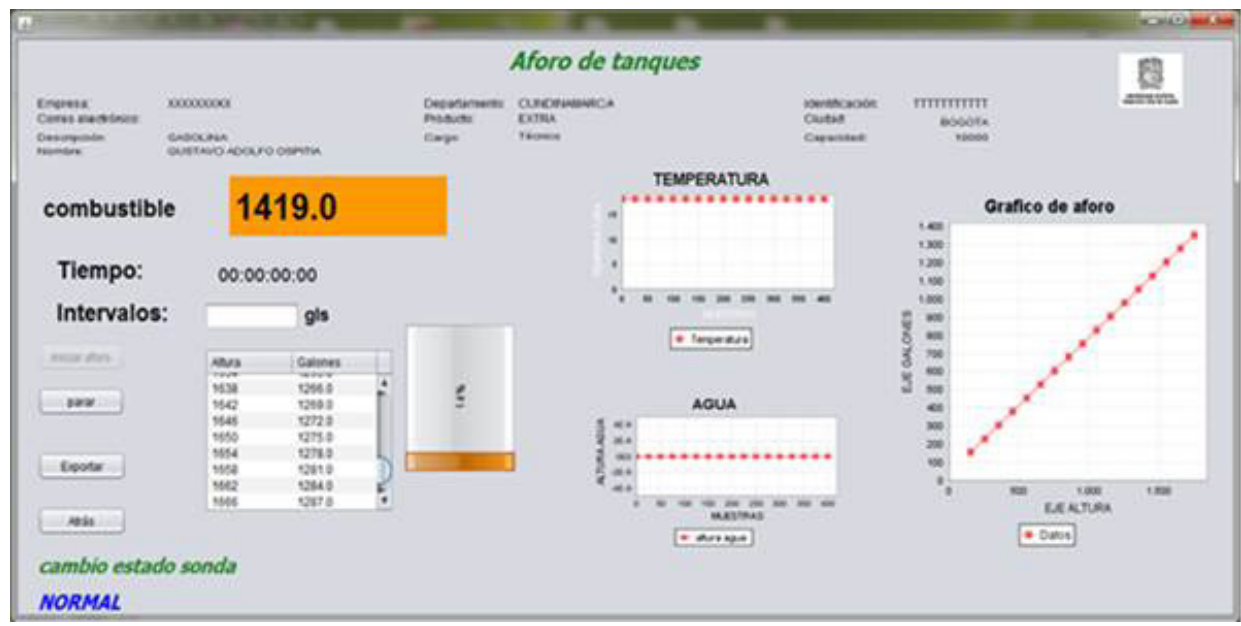

Figure 14. Process display form.

\subsubsection{Reports}

The gauging table is generated in two ways:

- By pressing the export button and save it in the computer directory.

- When pressing the stop button or finish the capacity automatically.

Of the two forms you can create an Excel file with all the capacity data, the corresponding information, the observations, the signature of the responsible person and the resolution of millimeters in order to deliver a customized table and calibration with the instrument of height measurement the client's.

\section{Results}

Four tests were carried out at gas stations located in: Garzón (Huila), Chicoral (Tolima) and two (2) in Agua de Dios (Cundinamarca). Each one at different environmental conditions, material, type and size. Table 2 shows the characteristics of each of the tanks used in the tests.

Table 2. Characteristics of the test tanks

\begin{tabular}{|l|l|l|l|l|l|}
\hline Tank Location & Product & Temp. $\left({ }^{\circ} \mathrm{C}\right)$ & Capacity $($ Gls $)$ & Material & Type \\
\hline Garzón & Gasoline & 20 & 12000 & Fiberglass & Underground \\
\hline Chicoral & ACPM & 37 & 10100 & Metallic & Shallow \\
\hline Agua de Dios & Gasoline & 31 & 6000 & Fiberglass & Underground \\
\hline Agua de Dios & ACPM & 31 & 6000 & Fiberglass & Underground \\
\hline
\end{tabular}


The results obtained from the four tests are shown in the following graphs of (Figure 15) delivered by the

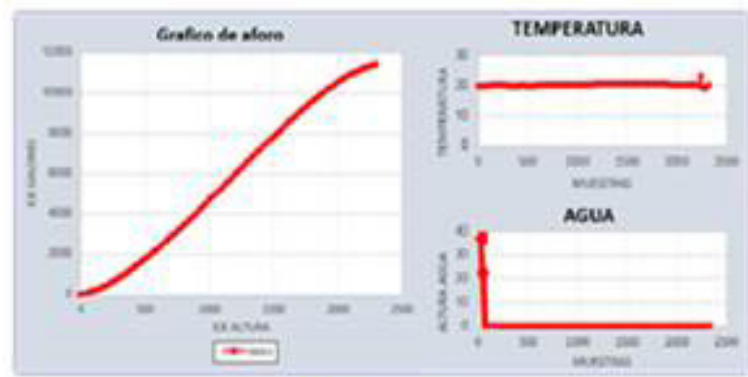

Garzón-Corriente

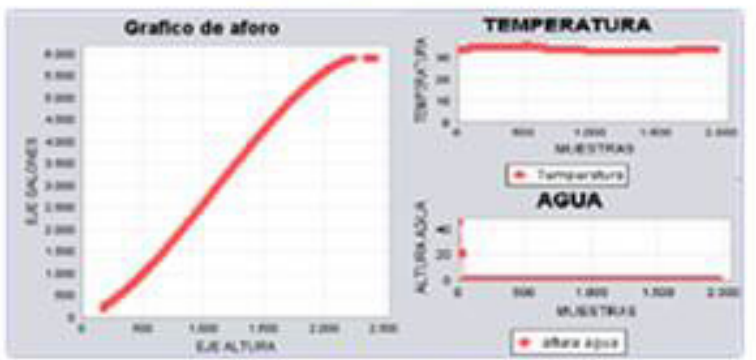

Agua de Dios- Acpm volume and fuel height matching software; water and temperature.

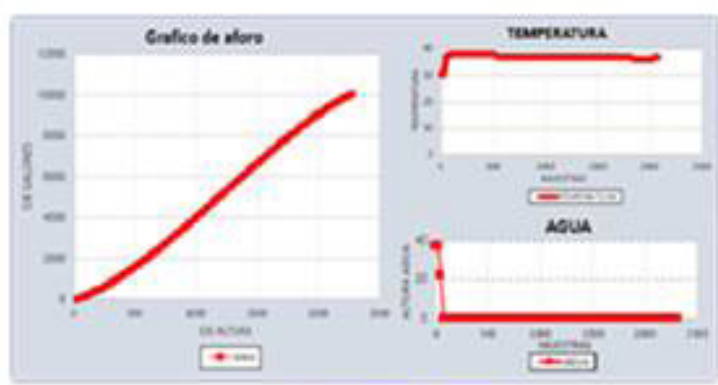

Chicoral-Acpm

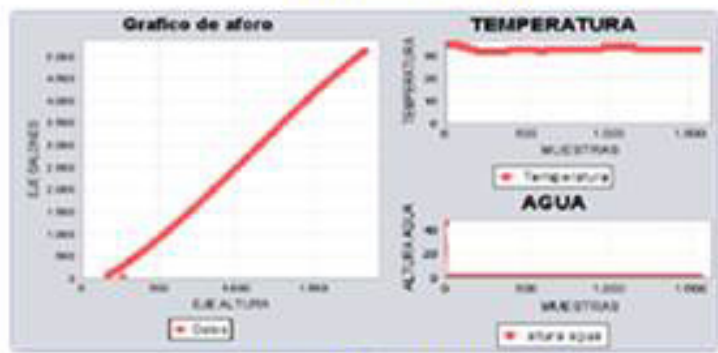

Agua de Dios-Corriente

Figure 15. Gauging graphs of the 4 tests.

The volumetric tanks have a cubic behavior, being notable in large tanks; it also shows a regularity of the temperature in the majority of the process, as well as the lack of water in the tank thus complying with the normative parameters (water less than $10 \mathrm{~cm})^{5}$; except in the first data because the floats of the fuel and water sensor are continuous generating a magnetic field resulting from the sum of each one.
The verification of the tests is carried out during the following 7 days, the reference being the yard sales of the fuel dispensers against the height measurement of the instrument of the station (typically rule), previously calibrated with the magnetostrictive probe with the objective of Observe and compare with the value provided in the table. The results are shown below in Figure 16.
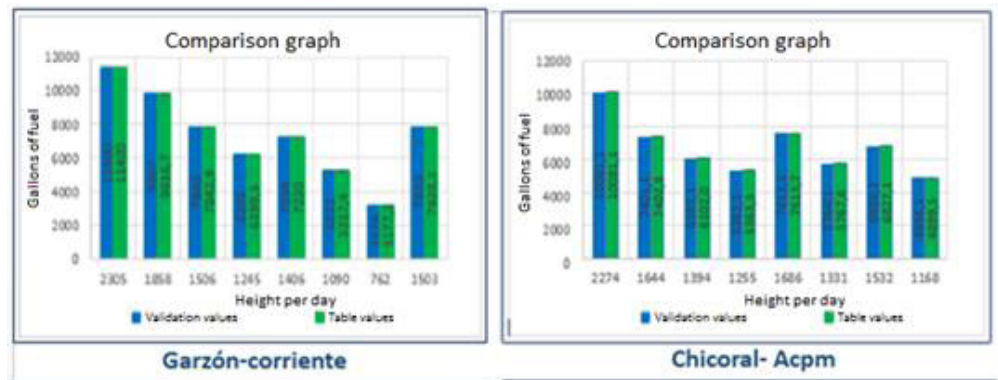

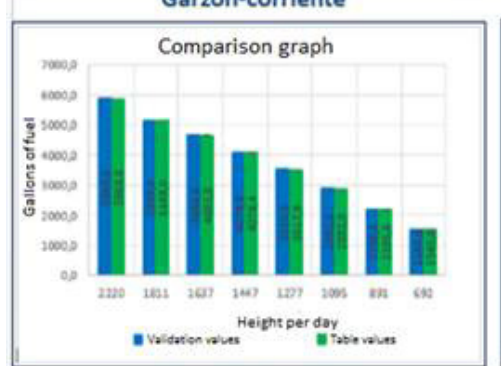

Agua de Dios-Acpm

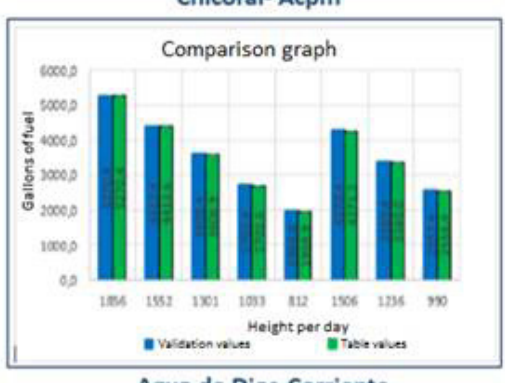

Agua de Dios-Corriente

Figure 16. Validation results. 
The comparison of the results analyzed shows the absolute errors and relative errors of the system. Absolutes help to know the precision of the measurement and the relative percentage of the total system (Figure 17).
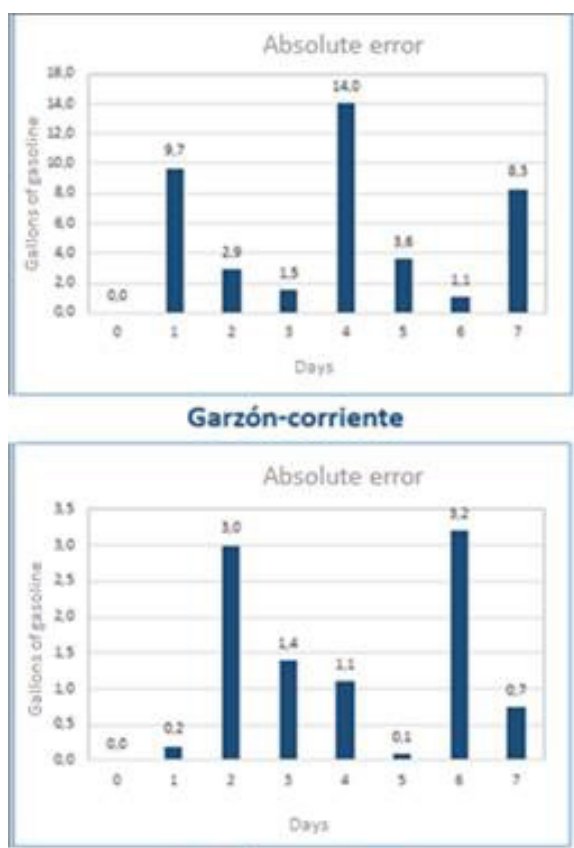

Agua de Dios-Acpm

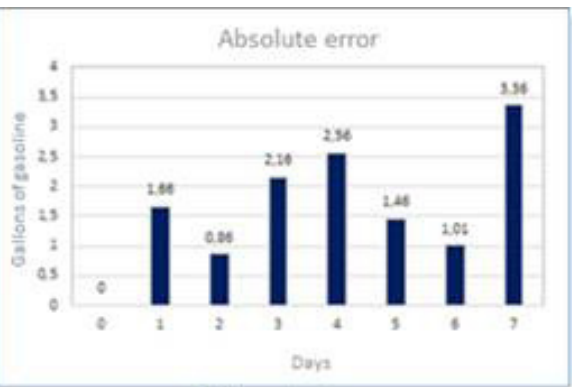

Chicoral-Acpm

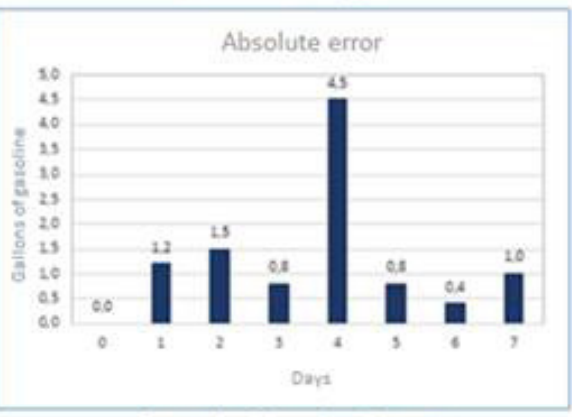

Agua de Dios-Corriente

Figure 17. Absolute errors of the tests.

The errors show a precision of up to 14 gallons, thus being more prone to error in larger capacity tanks (Figure18).

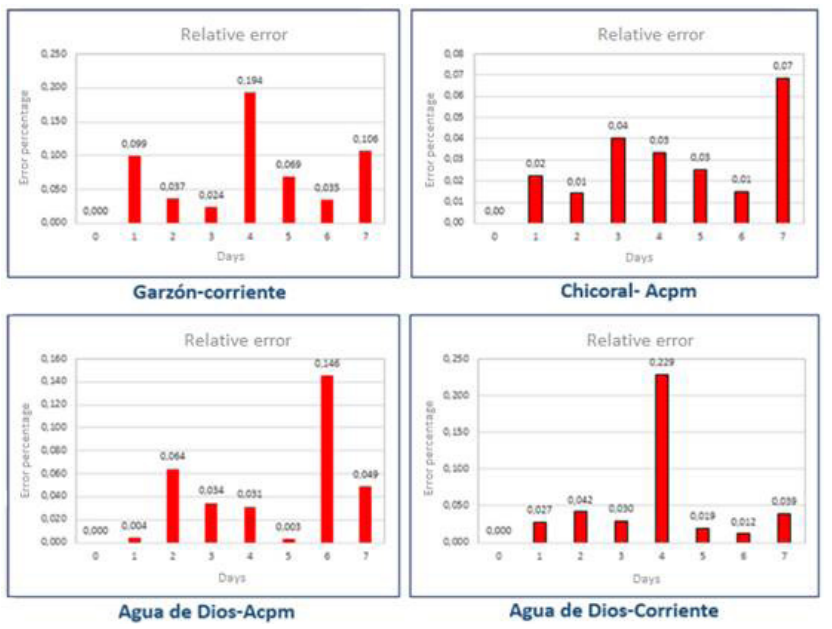

Figure 18. Test error rate.

Absolute errors show a maximum error of 14 gallons, a total average of 2.64 gallons and an average of 1.5 for most tanks except for Garzón with 5.87 gallons. While relative errors show a maximum error rate of $0.229 \%$, less than the $0.5 \%$ stipulated in ${ }^{5}$. Validating the reliability of the system with respect to stored fuel ${ }^{13}$.

\section{Conclusions}

For the development of the project, continuous and high flow electronic gauging system for liquid fuel tanks, it was necessary to know and obtain information about the current systems status; projects were found only in surface tanks, but the empirical method in underground tanks is known, which is executed through partial measurements of 50 gallons, causing unreliable tables due to human errors and variation of height with the volume partially entered.

The background phase served as a guide for the realization of it and takes the best of both forms. First of all, it was initiated by designing a communication and flow control card, in charge of acquiring and analyzing the pulses supplied by the flow detector cards, controlling flow types and bidirectional communication; the mean reason to achieve a system of continuous measurements and a hydraulic circuit in charge of delivering flows of up to 100 gallons per minute compared to the market standard found in 50 .

See the gaging system software based on the JAVA programming language, responsible for providing a friendly and intuitive user interface and reliability through authentication; then sequentially guide between forms to 
the gauging process, when obtaining the information provided in the configuration forms.

The gauging process contains a real-time visualization by the use of multi-threads, responsible for managing graphics and logic together, providing efficiency and independence of each process; Reason to obtain from the serial ports simultaneous data that are immediately shown, tabulated and plotted.

The program in addition to the visual interaction, is flexible before the graphic and tabulated reports, because the user can choose; For the graphic report you can vary scale, color, zoom and other properties; while the tabulated reports are directed to the Excel program, with the objective that the user chooses the presentation, resolution and the storage route of his preference.

To obtain reliable results (errors less than $0.5 \%$ ), the proportional relation of flow to size must be taken into account in order to have millimeter resolutions. The generation of a table with millimeter resolution is intended to be customizable by the user (usually every 5 millimeters) and calibrated with its measurement bar, which has previously been compared with the probe, to deliver the corresponding equivalences.

\section{References}

1. Russi LJ, Castillo JP. Dise-o y construcción de un sistema para aforar tanques de almacenamiento de cerveza terminada. Universidad San Buenaventura; Bogotá, Colombia. 2006. p. 1-207.

2. Espinoza MR. Estudio de la calibración volumétrica de los tanques de almacenamiento en el centro de facilidades de producción en la estación lago agrio $\mathrm{N}^{\circ} 1$. Universidad tecnologica equinoccial. Facultad: ciencias de la ingeniería. Quito, Ecuador. 2009. p. 1-14.
3. Cruz FAS. Desarrollo de un sistema de adquisición, procesamiento y evaluación de datos de tanques y equipos de inspección de líneas de transporte de hidrocarburos: Panametrics, PCM y CIPS mediante el uso de labviews/ Fabio Andrés Salinas Cruz. Universidad Surcolombiana, Neiva, Colombia; 2008. p. 1-60.PMCid:PMC3154615

4. Parra JRV. Implementación de robot radio de control para medición de verticalidad de tanques en servicio de aforo de tanques prestado por ATP ingenieria LTDA. Universidad Surcolombiana, Neiva, Colombia; 2009.

5. Del Medio Ambiente M. Guía de manejo ambiental para estaciones de servicio de combustible. Bogotá, Colombia; 1999.

6. Barnes de Colombia. Catlogo de Curvas-barnes de Colombia; 2014.

7. Rodriguez AB, Sánchez JAF, Jeta JAL. Medida y evaluación de las extracciones de agua subterránea. IGME; 1999.

8. Czekaj D. Aplicaciones de la ingenieria: Maquinaría hidráulica en embarcaciones.Food and Agriculture Organization. 1988. p. 1-202.

9. De ambiente M, y desarrollo territorial V. Decreto número 4741 de 2005. El Presidente De La República De Colombia. Bogotá, Colombia; 2005. p. 1-25.

10. Pinzón RP. Manual de medición de tanques de almacenamiento de productos derivados del petróleo. Universidad Surcolombiana, Neiva, Colombia; 2000.

11. VEEDER-ROOT. Mag probe assembly manual. VeederRoot, Revision: G; 2009. p. 1-9.

12. VEEDER-ROOT. Veeder-Root TLS2 Console Gilbarco EMC2 Console.Setup and Operation Manual. Software Version 6; 2011. p. 1-85.

13. De Minas y Energía M. Decreto 1521 de 1998.El Presidente De La República De Colombia. Esta norma no incluye análisis de vigencia expresa; 1998. p. 1-27. 